How to cite:

Niyomugabo, C., Sibomana, E., \& Niyibizi, E. (2018). A reflection on the need for a language management scheme at the university of Rwanda's college of education. International Journal of Humanities, Literature \& Arts, 1(1), 1 10. https://doi.org/10.31295/ijhla.v1n1.28

\title{
A Reflection on the Need for a Language Management Scheme at the University of Rwanda's College of Education
}

\author{
Cyprien Niyomugabo \\ University of Rwanda - College of Education \\ Corresponding author email: niyomugabocyprien@gmail.com \\ Emmanuel Sibomana \\ University of Rwanda - College of Education \\ Epimaque Niyibizi \\ University of Rwanda - College of Education
}

\begin{abstract}
The issue of language policy and management has been tackled by various scholars worldwide, but gaps are observed in studies that explored the language management schemes in schools, particularly in institutions of higher learning. This paper contributes to filling this gap by reflecting on the need to design a language management scheme for the University of Rwanda's College of Education to promote language proficiency and quality education. Using Gundersen's language management model as a theoretical framework and drawing from an analytical approach, this article explores the urgent need for developing the language management scheme at the University of Rwanda-College of Education. It highlights the enablers and challenges for developing and implementing such a language management scheme and recommends some strategies to capitalize on those enablers to solve language problems at the College. Throughout the paper, our argument is that a language management scheme is needed for the promotion of the proficiency in all five languages used at the College generally, and in English particularly, which is used as a medium of instruction.
\end{abstract}

Keywords---language management, language needs, language policy, multilingualism, Rwanda.

\section{Introduction}

The proficiency in French, English, and Kiswahili by most of the educated people in Rwanda, including university graduates, has been questioned by several research studies (Kagwesage, 2012; McGreal, 2009; Pearson, 2014; Niyibizi, 2015; Sibomana, 2015, 2016). This situation is a cause for concern given that these languages are the only ones which help Rwandans to connect to the rest of the world. With specific reference to English, this language is increasingly becoming a global lingua franca (Altbach, 2004; Bhatt, 2001; Samuelson \& Freedman, 2010) and is associated with power, prestige, decent jobs and many other advantages. As a result, there is a massive drive to acquire proficiency in this language whatever the cost to individuals, communities, institutions, and nations (Crystal, 2003) and this drive is felt more in the educated communities. It then follows that learning institutions need to equip their students and staff with the required level of proficiency in English and other possible languages before it is too late. In order for this to be achieved, we suggest that all institutions need to have language management schemes; and our analysis of the language management situation and needs at the University of Rwanda - College of Education (UR-CE), which is the focus of this paper, is a reflection of such a necessity. The paper reflects on why UR-CE urgently needs to develop the language management scheme, points out the enablers and challenges for language management within the UR-CE community and recommends some strategies to capitalize on those enablers so as to solve the identified challenges. It attempts to answer the following four research questions:

a) Why does UR-CE need a language management scheme?

ISSN 2632-9441

Received Jan 10, 2018 / Accepted Jun 20, 2018 / Published Jul 05, 2018 
b) Is there willingness and ability on the part of UR-CE to accommodate the language needs of its staff and students?

c) Does UR-CE have the required level of competence which will enable it to respond to the current language needs of its community members?

d) Do the UR-CE policies and strategies aim at addressing the language issues which the College is facing?

In order to reflect on these questions critically, the paper has adopted an analytical approach, which is used in "providing insights into current educational events, issues and policies, by applying internal and external criticism; identifying facts and constructing interpretative explanations to those facts" (McMillan \& Schumacher, 2006). Although analytical research focuses mainly on educational concepts, educational historical events and oral history (McMillan \& Schumacher, 2006), it was found appropriate to inform this study because educational policies are in line with educational issues or events. This analytical research also sets the ground for further empirical studies on these educational issues. In addition, Gundersen's (2009) model on language management at institution level was found to be an appropriate theoretical framework to guide this reflective analysis and answer the above-mentioned questions.

\section{Research Methods}

\section{Theoretical framework}

Generally, the use of languages in (a) given context(s) is determined by language policy which may be explicit or implicit. According to Spolsky (2007), language policy has three interrelated components, and these are practices, beliefs and management. This scholar indicates that language practices are observable behaviours and choices or what people actually do with language. Beliefs are the values assigned to language varieties and features, while language management, which is our focus in this analysis, refers to "the explicit and observable effort by someone or some group that has or claims to have authority over the participants in the domain to modify their practices or beliefs" (Spolsky, 2007). As implied in Spolsky's description above, it appears that the nature of language practices and beliefs largely depends on language management. However, as Spolsky goes on to argue, language practice is the strongest of the three because in its absence, "there is no available model of language to learn" (p. 4), which makes language management difficult. In this regard, we are using a language management model developed by Gundersen (2009) in order to suggest a language management scheme that would address the language needs of educators, staff and students of the University of Rwanda's College of Education, taking the three components into consideration. The model is as follows:

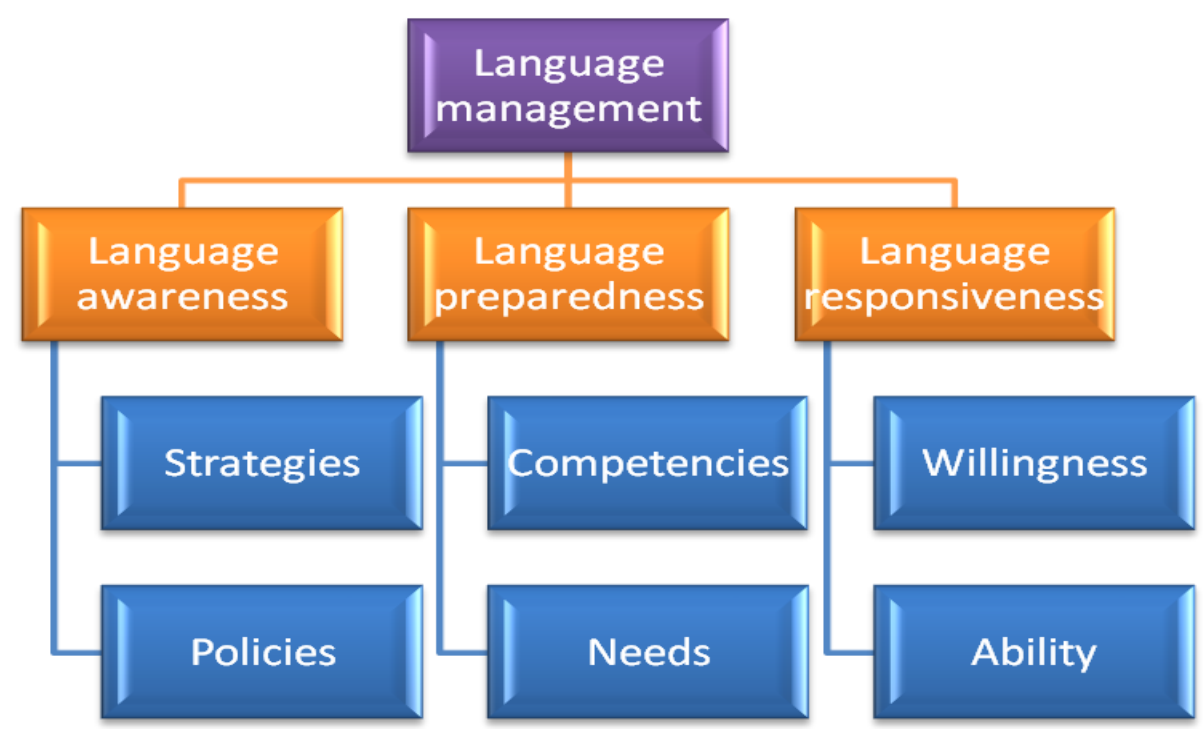

Figure 1. Staff and students of the University of Rwanda's College of Education 
While Gundersen (2009) developed this model for business companies, we suggest that it can be applied to any organization, including learning institutions. As can be seen from the model, language management is determined by three major factors: language responsiveness, language preparedness and language awareness. Language Responsiveness is the willingness and ability of the company to accommodate the language needs of their international partners. In relation to the UR-CE, the partners include its staff and students, who have various language needs which need to be satisfied in order to effectively provide and access the services offered by the institution. Language Preparedness is the level of language competence possessed by the company expressed against current and anticipated needs or, in other words, the organization's readiness to respond to the needs. Language Awareness is the extent to which language issues are embedded into the strategies and policies of the company. Gundersen (2009) indicates that "a language-aware company would explicitly question the availability of adequate language skills, conduct periodic assessments of language skills against needs, and maintain an inventory of in-house language skills." We will use this model to explore the needs, the enablers and the challenges that are available at the UR-CE, as well as the possible strategies to overcome these challenges.

\section{Results and Analysis}

\section{Critical reflection on current situation of language management at UR-CE}

This section discusses the current situation at UR-CE in regard to language management. The discussion focuses on the conditions which justify the need for a language management scheme at UR-CE, the enablers, and challenges at stake as well as the strategies to capitalize on those enablers and solve the challenges.

\section{The need for language management scheme at UR-CE}

Based on Feely \& Winsow's (2006) definition, language management is the extent to which a company is able to satisfy its language needs through prudent deployment of a variety of language management tools including, for example, language training and expatriation. Drawing on this definition, it is clear that language management is of paramount importance for teaching institutions because, as Spolsky (2007) argues, "schooling is, by its very nature, a domain committed to language management". Thus, in addition to its own language management, UR-CE, as a teacher training institution, also has a big stake in what happens in schools regarding language management. As a result, this institution needs to have a strong and relevant language management scheme which can serve as a model for schools and even other higher learning institutions. This scheme, we suggest, should help to identify and respond to the language needs of its population and, at the same time, promote all the four official languages and Chinese, putting more emphasis on English, which is the main language of instruction at this institution.

Regarding the current situation at UR-CE, it is observed that this institution does not have a well-elaborated language management scheme, but we are cognizant that it has some sporadic guidelines on language use in academic affairs, such as in teaching and assessment. However, the guidelines on language management and use in other areas of URCE's life are not developed yet and they need to be worked out based on enablers and challenges for language management. The next section reflects on these.

\section{Contextual enablers for language management within UR-CE community}

As Weinstein (1990); Francis \& Kamanda (2001); Shohamy (2006) have indicated, language policy, planning and management encompass deliberate decisions and choices of language form, language functions as well as language acquisition strategies that are made by institutions to solve language problems. UR-CE, like other education institutions, strive to solve language problems for quality education because it is well known that the medium of instruction strongly affects quality education (see Brock-Utne 2012; Coleman 2011; Ogechi 2009; Williams 2011). In order to achieve a balanced and effective language management, there are enablers which need to be capitalized on and challengers which need to be addressed. To explore these enablers and challengers, we have used Gundersen's (2009) model, which singles out some pillars that help us highlight the contextual enablers and challengers for language management within UR-CE community.

The pillars of this model include language preparedness, language responsiveness, and language awareness, as explained in the theoretical framework above. With reference to language responsiveness, we opine that UR-CE may be willing and able to respond to the language needs of its community members but this ability and willingness have 
not been translated into practical steps. In the first place, these needs have not been identified. Thus, there is a need for a systematic in-house language skills identification process which will give a picture of where the College is currently, in comparison with the intended destination. This will help in designing policies, strategies and plans to get there. The assessment of these needs should be done periodically so as to be aware of any change.

With reference to language preparedness, it appears that the College has the required competence to respond to the current language needs of its population. This institution has a language section in which language specialists educate high school teachers of Kinyarwanda, English, French, and Kiswahili. In addition, the College offers communication skills course to its students and the lecturers who teach this module are believed to be qualified. This institution also happened to design programs for teaching languages to its academic and administrative staff; it used to be a language learning center in the past and has recently initiated a language and literacy education innovation center. What needs to be revisited, we suggest, are the policies and strategies which are in place and dictate how these lecturers' and administrative staff's competence is channeled.

As for language awareness, it seems that UR-CE has not embedded language issues into its strategies and policies. In other words, UR-CE does not have a clear language policy which would specify how the different languages should be acquired and used at the College. Explored from the perspective mentioned above, an outlook of language situation at UR-CE and in Rwanda generally reflects both enablers and challengers which have a bearing on language management at this institution.

The Rwandan language policy favors multilingualism and multiliteracies by recognizing three official languages (Kinyarwanda, English, and French, together with Kiswahili which has recently been added to the three), and makes the provision for them to be taught as school subjects at all levels of education. The emphasis on the mother tongue (Kinyarwanda) has also attracted the attention of the country's top management because one of the resolutions of the Umushyikirano (the National Dialogue ${ }^{1}$ ) recommends the teaching of Kinyarwanda at all levels of education in Rwanda in order to preserve it. Moreover, the three official languages and Kiswahili are taught (and used to varying extents) at UR-CE. Therefore, the status and functions of these languages at UR-CE and in the country at large offer opportunities to learn and use all these languages. For instance the domination of Kinyarwanda in daily communication, the use of English as a medium of instruction at UR-CE, the teaching of the different languages as school subjects, the use of Kinyarwanda, English, French and Kiswahili for literary or scholarly purposes and the teaching of Chinese as a foreign language make UR-CE a linguistically diverse community or, in other words, a language melting pot. This situation has brought about an array of linguistic phenomena which enrich communication at this institution. These include code-switching and trans languaging, which have given rise to a new language variety used by UR-CE students, which Niyomugabo (2012) described as 'Kinya-fra-anglais' born from the mixing of Kinyarwanda, French and English. In addition, there are a number of language activities which create practical linguistic diversity at the College. These include language use for cultural, religious and/or ritual purposes. These activities enhance multilingualism and multiliteracies since some of them are carried out in Kinyarwanda, English, French, Kiswahili and Chinese or a combination of all these.

In addition, the fact that most of the languages which are taught and used at the two campuses of UR-CE (Remera and Rukara) have an international scope is also an enabler; it offers a number of benefits associated with proficiency in these languages. English and French are international languages of scholarship; Kiswahili is a regional and official language for the East African Community, while Chinese is gaining more ground in international business. This situation is a motivating factor for learning these languages.

\section{Contextual challengers related to language management at UR-CE}

In spite of the above enablers, however, there are a number of challenges which need to be addressed if the institution wants to have an adequate language management. Some of the key challenges are highlighted below.

The first key challenge is the limited information about UR-CE community members' attitudes towards languages. Building on Barkhuizen et al., (2006) and Spolsky's (2009) argument, students, teaching staff and professional administrators in teaching institutions bring with them language preferences, practices, and beliefs, which are sometimes not recognized, while they should constitute the basis for the institution's language management. Up to now, it appears that the attitudinal orientations of UR-CE students and staff towards the different languages are not well known because no study has investigated them deeply. This information should inform the

\footnotetext{
${ }^{1}$ Umushyikirano is an annual forum that brings together leaders and citizens to discuss the country's development (http://umushyikirano.gov.rw/). It is during this forum that the President presents his National Address.
} 
design of interventions and the lack thereof may hamper the effectiveness of these interventions because language attitudes have a strong bearing on language learning effectiveness (Dehbozorgi 2012; Ushida 2005).

Another challenge is the lack of clear guidelines on language use in the college: in classes, in offices, and on the UR-CE premises. More specifically, UR-CE does not have guidelines for the management of communication between the different categories of people in this community: students, lecturers, administrative/support staff. In other words, except for the classroom where English is supposedly used as a medium of instruction, language use in other contexts is unpredictable. This situation makes it difficult to know the role which each language plays in communication at the college.

The lack of information on the effectiveness of language teaching programs in place or current language teaching pedagogies is another challenge. For example, the program for teaching English to all UR-CE staff which started in 2009 was stopped in 2011. However, there was no evaluation to check whether the program reached its objectives, whether all the staff had been trained thoroughly in English; and whether there was no need for programs to teach other languages such as Kinyarwanda, French, Kiswahili, and Chinese to UR-CE staff. The lack of information about strengths and weaknesses of such programs, which could inform subsequent interventions, is a serious challenge.

\section{Strategies to capitalize on the enablers and address the identified challenges}

Based on the enablers and challengers discussed in this paper, we suggest a number of strategies which, if well applied, could lead to an effective language management scheme for the College. As has been pointed out, language issues appear to have not been given the attention which they deserve in the strategic planning of the UR-CE and, therefore, the language needs of the UR-CE community members are not well known. That is why we observe a number of challenges in language management at UR-CE, as highlighted in the previous section. To address those challenges, some strategies need to be applied, and this section suggests the salient ones.

\section{a) Conducting an in-house investigation of UR-CE Community members' language needs}

There is a need for an in-house investigation of the language needs of the community members in all the four languages with an official status in Rwanda (Kinyarwanda, English, French, and Kiswahili) and in other languages used at the College such as Chinese. This information may help in designing a program for addressing the current language needs, from a short and long-term perspective. In order to work proactively in addressing language needs at the institution, there is a need for a language management scheme for the College, in the development of which, both the students and staff need to play a role. Indeed, without proficiency in the different languages used at UR-CE, the achievement of the College's mission is hardly possible. In addition to specifying the areas, settings and times where and when the different languages should be used in the college, the language management scheme will also suggest better strategies and approaches teach and use these languages effectively.

\section{b) Setting up guidelines for a quadrilingual policy at UR-CE}

Another strategy which supplements the previous one is to set up guidelines for a quadrilingual policy at UR-CE. It has been indicated previously that the use of different languages at the UR-CE is unpredictable because there are no guidelines on how they should share the space and functions Calvet (1987) at the College. Thus, such guidelines are needed. For instance, English and French could be used in activities of the academic nature (classes, conferences, and seminars, etc.) because dual immersion (or teaching in two languages) has proven to be effective Cazabon et al., (1995) and an important tool to achieve functional bilingualism (Castellotti 2001). These two languages could also be used in daily communication, in offices between academic, administrative staff and students, so as to offer opportunities to practice them. Kinyarwanda could be used for social, cultural and religious activities and Kiswahili for sports activities. In this way, people will know where and when to use the different languages. All the languages should be valued because they all play a role in communication at the College.

\section{c) Sensitizing the UR-CE community on early bilingualism}

To overcome the challenges highlighted above, all the people in the UR-CE community need to be sensitized on what Lanchec (1976) described as early bilingualism. They need to be made aware that UR-CE strives to make every student and staff proficient in at least two languages: English and French. People may vary in their ability to use these languages, with some achieving functional proficiency while others can be highly proficient, literate and knowledgeable in the two or more languages. However, English should receive more attention because, in addition to 
being offered as a school subject, it is used as a medium of instruction at all levels of education. Therefore, the aim of policy makers and language teachers in Rwanda should be to see English move from being a foreign language to become a second language in Rwanda. In short, the UR-CE needs to have an appropriate policy to ensure that new UR-CE members with limited proficiency in English are equipped with the proficiency which enables them to access the curriculum and take part in academic and social activities using English. We, therefore, suggest that the language needs of all people who join UR-CE community be identified and related intervention organized. However, the people need to be motivated Gardner (1985) in order for their investment (Norton 2000) in the learning of these languages to be high. Thus, as has been noted, their attitudes towards these languages need to be investigated so that they can be responded to and/or managed effectively in the designing of the teaching programs.

\section{d) Improving the approaches for teaching foreign languages at UR-CE}

As some researchers for example (Amini, 2014; Sibomana, 2014) have noted, it appears that the approaches and methods which have been used to teach foreign languages in Rwanda have not been effective. The situation may also apply to the College of Education because it has had various language teaching programs but their effectiveness can be questioned. Indeed, its graduates, like those of other higher learning institutions in Rwanda have been said to have limited proficiency in the languages which they have studied and used as media of instruction. Therefore, we suggest a research-based reform of EFL/ESL/TESOL approaches searching for those which are more appropriate for the Rwandan context, in order to revolutionalize the teaching of foreign languages (see Guevara 2002; Dabène 1994) at the College and in the country at large. Language classroom conditions need to be improved if our language teaching programs have to reach their targets. For example, effective teaching/learning aids and resources need to be in place and teacher-student ratios need to be appropriate. In addition, we suggest a revision of the Foundations of English and Communication skills modules because they are key factors to the implementation of the College's language management scheme, which aims at developing students' literacy and communication knowledge and skills that will enable them to learn other subjects. Among other possibilities, we suggest that literacy and communication skills modules run across all levels (from Level 1 to Level 5) so that students can draw on the skills and knowledge gained in learning other modules progressively and continuously.

\section{e) Adoption of a 'literacy across curriculum' concept at UR-CE}

The adoption of the concept of 'literacy across the curriculum' (Seligeman, 2013; Unsworth, 2001) by all lecturers in all subjects taught at UR-CE is another strategy to curb the language and literacy-related challenges. In this regard, the teaching of literacy and communication skills should not be a territory for language teachers only. Every lecturer should feel that it is their role to improve their students' communication and literacy skills in their respective subjects. Otherwise, how will students understand chemistry, physics, geography, economics, information technology etc, if they are not able to access it though language? Indeed, "language wraps itself around, in, through and between everything that we teachers and learners do in the classroom" (Ritchhart, 2002). In addition, the language will be more meaningful when taught in the context of the particular subject or course in which the learner intends to use it. That is why the concept of 'literacy across the curriculum' needs to be understood and espoused by all partners in education.

One of the challenges that these lecturers might face is that some of them may not be very conversant with the language. This is the reason why we suggest that training is offered to such lecturers in order to enable them to use English as media of instruction. Such training could also address these lecturers' needs in academic literacy, like how to write and make sense of academic texts in English and/or French, Kiswahili, Kinyarwanda, and Chinese.

\section{f) Instilling the culture of reading among UR-CE community}

One of the strategies to learn a language is to read extensively the texts written in that language. The lack of a reading culture has been reported to be a problem in Rwanda, even among the educated people (Asaba, 2015; Mugisha, 2011). Thus, there is a need for strategies which promote the culture of reading at UR-CE. Lecturers should design their course and assessment tasks in such a way that they encourage reading: students should read to learn. In other words, they should be involved in reading activities as a requirement to pass their assignments and exams. Hence, we suggest, the culture of giving summaries for the students to rely on in their exams should be discouraged. They should read books, book chapters, academic articles, and other texts themselves and lecturers should help them in understanding these. 
In a similar vein, UR-CE teaching programs need to be revised so as to reflect an inquiry-based, task-based and communicative language teaching approaches. Indeed, the College aims at developing confident and professionally qualified graduates, teachers, scholars, other education professionals and lifelong leaders in a high-quality research environment that promotes engagement, reflection, creation and innovative response to community, national and global challenges ${ }^{2}$. We argue that this can be possible only when these graduates are highly proficient and enthusiastic readers, writers, viewers, presenters, speakers, and listeners. As a result, a constructivist approach should be adopted in all subjects encouraging inquiry, exploration, and investigation. This will bring the students to read extensively and to update themselves about current developments, leading to improvement in communicative abilities.

In addition to reading academic texts, students need to be encouraged to read for pleasure. This will help them to develop an interest in reading so that it is not a burden but a joyful experience. One challenge related to this recommendation is that books and other materials to read may not be available. In this regard, we suggest a revitalisation of the College's library in diverse hard copy and online reading materials (academic texts, novels, newspapers, magazines, religious and sports texts, etc.) in all languages used as UR-CE (Kinyarwanda, English, French, Kiswahili and Chinese) so as to meet the interest of various people and make them aware of current developments, to foster an interest in reading, and to develop confidence, fluency and understanding. This goes hand in hand with the provision of information and technology facilities such as internet connection to facilitate online learning and use of online materials, computers, printers and, if possible, language laboratory facilities together with enough reading space where students can work individually or in groups in a quiet and attractive environment (Fuller, 1987; Neke et al., 2004).

\section{g) Increasing opportunities for academic discussion forums}

It appears that academic fora for the students and academic staff to develop their academic knowledge and skills are very limited (if there are any). It is not clear how the College (and the University at large) can be a prominent academic institution when there are limited platforms for people to grow academically. Thus, academic conferences and seminars should be organized and multiplied in the College in order for students and lectures to share ideas on various issues affecting education at different levels and how academics can help in addressing those issues. In addition to developing academic knowledge and skills, such events will help people to improve their communication knowledge and skills because of the exchanges. Prominent academics and other guest speakers could be invited, which could motivate people to attend. However, even speakers from within the College could also speak on such occasions. As all College lecturers have done research in various areas, sharing their findings with colleagues should be one way of disseminating this knowledge. Such fora could also be established at the departmental and sectional level where lecturers and students from the same specialization can discuss issues affecting the teaching of their subjects at primary, secondary and tertiary levels. In addition to being an opportunity for the students and lecturers to improve their communicative abilities, such discussions could play a pedagogical role in the College. Moreover, reading and writing competitions need to be organized for the students, with the prizes to be given to the best readers and writers. The student Union Newspaper (Le Moment) which used to write mainly about the life at the College should be revived and supported because it is a platform for the students to practice their writing and reading skills. We also suggest a Language and Literacy Education Centre which could be in charge of implementing the UR-CE's language management scheme. Part of its mission could be to address students' and lecturers' needs in academic and creative writing, proofreading and editing journal articles and book chapters, because these are the core for the achievement of the College's mission.

\section{h) Revitalization of language clubs at UR-CE}

In order to provide students with more opportunities to practice the foreign languages, language clubs should be created and supported by the College. Events should be organized in the college where the students in these clubs could do various performances, which may develop these clubs to the level of performing even outside the College. Those language clubs should encourage all the languages used at UR-CE (English, French, Kinyarwanda, Kiswahili, and Chinese) as well as numerous celebrations and events linked to the diverse cultures within the community so as to promote a cosmopolitan spirit and an appreciation of different cultures. In trying to open the UR-CE to the English world, the College could offer internships in, and also receive interns from, English speaking countries.

\footnotetext{
${ }^{2}$ http://www.ce.ur.ac.rw/about/mission-and-vision
} 


\section{i) Need for a Language Management Committee at UR-CE}

In order for all the above measures, strategies, and plans to be effectively planned, there is a need for a Language Management Committee at the college. The committee would be in charge of carrying out an investigation of the linguistic situation at the college, design a detailed language management scheme which will best address the language needs of this institution and follow up its implementation. Among other tasks, the Committee could advise and assess language teaching programs, make recommendations on possible languages that need to be taught and advise the College management on how language issues can be embedded in the College's strategic plan, academic regulations and policies. While we are observing various practices among our university students such as codemixing (Niyomugabo, 2008), code-switching and trans languaging (Garcia, 2009; Makalela, 2014; Kagwesage, 2013) and simultaneous use of different languages in the same lesson (Niyibizi, 2015), this committee may advise on how best these practices can be beneficial.

\section{Conclusion}

This paper has explored the necessity for a language management scheme to promote multiliteracy and multilingualism at UR-CE. While no language needs analysis has been conducted in the College, the proficiency of its students and staff in English has been reported to be generally limited. This may be a hindrance to the achievement of the College's mission, including providing quality education. Some of the reasons for this situation appear to be inappropriate language teaching approaches and methods and the lack of a language management scheme at this institution that could regulate the use and the teaching of the different languages. In spite of this situation, however, there are numerous enablers for the development of an effective language management scheme at the College, which, we argue, need to be capitalized on in addressing the challenges in English language proficiency development. Those enablers include the expertise of the lecturers at this institution; the favorable national language policy and the linguistic landscape at the College, which promote multilingualism and multiliteracies.

\section{Acknowledgements}

The author would like to thank the editor for their valuable time and advice. 


\section{References}

Adetunji, A. T., Adetunji, A. V., Adeleke, E. O., \& Madubuike, S. C. (2017). Deregulation: The Effect of Market-led Approach to Nigerian Universities Management. International Journal of Social Sciences and Humanities (IJSSH), 1(1), 1-8.

Baker, C. (2011). Foundations of bilingual education and bilingualism (Vol. 79). Multilingual matters.

Baldauf Jr, R. B. (2004). Language planning and policy: Recent trends, future directions. In American Association of Applied Linguistics (pp. 1-8).

Best, J. W., \& Kahn, J. V. (2016). Research in education. Pearson Education India.

Brock-Utne, B. (2012). Language and inequality: Global challenges to education. Compare: A Journal of Comparative and International Education, 42(5), 773-793.

Calvet, L. J. (1987). La guerre des langues et les politiques linguistiques. Paris: Payot.

Castellotti, V. (2001). La langue maternelle en classe de langue étrangère (p. 124). CLE international.

Coleman, H. (2011). Developing countries and the English language: Rhetoric, risks, roles and recommendations. Dreams and realities: Developing countries and the English language, 9-21.

Creese, A., \& Blackledge, A. (2010). Translanguaging in the bilingual classroom: A pedagogy for learning and teaching?. The modern language journal, 94(1), 103-115.

Dabène, L. (1994). Repères sociolinguistiques pour l'enseignement des langues: les situations plurilingues. Hachette.

De Dieu, A. N. J. (2014). An analysis of the treatment of writing pedagogy in three ELT textbooks for grade 4 learners in Rwandan primary schools (Doctoral dissertation, Faculty of Arts, University of the Witwatersrand, Johannesburg).

Dehbozorgi, E. (2012). Effects of attitude towards language learning and risk-taking on EFL student's proficiency. International Journal of English Linguistics, 2(2), 41.

Fabunmi, F. A., \& Folorunso, O. (2010). Poor reading culture: A barrier to students' patronage of libraries selected secondary school in ado local government area of Ekiti-State, Nigeria. African Research Review, 4(2).

Faulkner, J. (2003). Teaching multiliteracies across the curriculum: Changing contexts text and image in classroom practice. Australian Journal of Education, 47(3), 303-305.

Feely, A. J., \& Harzing, A. W. (2003). Language management in multinational companies. Cross Cultural Management: An International Journal, 10(2), 37-52.

Feely, A., \& Winslow, D. (2005). Talking sense. A research study of language skills management in major companies. In London: CILT, National Centre for Languages (UK). http://centrallobby. politicshome. com/Resources/epolitix/Forum\% 20Microsites/Centre\% 20for\% 20Information\% 20on\% 20Language\% 20Teaching/talking_sense. pdf.

Francis, D. J., \& Kamanda, M. C. (2001). Politics and language planning in Sierra Leone. African Studies, 60(2), 225-244.

García, O., Rubdy, R., \& Alsagoff, L. (2014). Countering the dual: Transglossia, dynamic bilingualism and translanguaging in education. The global-local interface and hybridity: Exploring language and identity, 100118.

Gutiérrez, R. B. O., \& Moreira, L. M. Z. (2018). The Profile of Executive Secretaries and Their Relationship with Labor Demands. International Journal of Social Sciences and Humanities (IJSSH), 2(1), 75-83.

Habyarimana, H., Ntakirutimana, E., \& Barnes, L. (2017). A Sociolinguistic Analysis of Code-Switching in Rwanda. Language Matters, 48(3), 49-72.

Kagwesage, A. M. (2012). Higher Education Students' Reflections on Learning in Times of Academic Language Shift. International Journal for the scholarship of teaching and learning, 6(2), n2.

Krieger, J., \& Crahan, M. E. (Eds.). (2001). The Oxford companion to politics of the world. Oxford; New York: Oxford University Press.

Lanchec, J. Y. (1976). Psycholinguistique et pédagogie des langues (Vol. 54). Presses universitaires de France.

Makalela, L. (2014). 6 Teaching Indigenous African Languages to Speakers of Other African Languages: The Effects of Translanguaging for Multilingual Development. Multilingual universities in South Africa: Reflecting society in higher education, $97,88$.

Makalela, L. (2015). Translanguaging practices in complex multilingual spaces: A discontinuous continuity in postindependent South Africa. International Journal of the Sociology of Language, 2015(234), 115-132.

Marie, K. A. (2013). Coping with English as language of instruction in higher education in Rwanda. International Journal of Higher Education, 2(2), 1.

Meierhenrich, J. (2014). Genocide: A reader. Oxford University Press USA. 
Niyibizi, E. (2015). The Rwandan teachers' and learners' perceived speaking proficiency in both Kinyarwanda and English after 2008-2011 consecutive language-in-education policy shifts. Rwandan Journal of Education, 3(1), 91-116.

Ogechi, N. O. (2009). The role of foreign and indigenous languages in primary schools: The case of Kenya. Stellenbosch Papers in Linguistics PLUS, 38, 143-158.

Phillipson, R. (1996). Linguistic imperialism: African perspectives. ELT journal, 50(2), 160-167.

Shohamy, E. (2006). Language policy: Hidden agendas and new approaches. Routledge.

Sibomana, E. (2014). The acquisition of English as a second language in Rwanda: challenges and promises. Rwandan Journal of Education, 2(2), 19-30.

Sibomana, E. (2015). The roles of Kinyarwanda and English for high quality education: New directions for the future. New directions in language and literacy education for multilingual classrooms in Africa, 123-151.

Sibomana, E. (2016). 'We know what to say, we know what to write, but we don't know how': the challenges of becoming academically literate in a new linguistic and socio-cultural space. Education as Change, 20(2), 123124.

Spolsky, B. (1989). Conditions for second language learning: Introduction to a general theory. Oxford: Oxford University Press.

Spolsky, B. (2009). Towards a theory of language management. Language management. Cambridge: Cambridge University Press, 1-9.

Suryasa, I. W., Prayoga, I. G. P. A., \& Werdistira, I. W. A. (2017). An Analysis of Students' Motivation Toward English Learning As Second Language Among Students In Pritchard English Academy (PEACE). International Journal of Social Sciences and Humanities (IJSSH), 1(2), 43-50.

Ushida, E. (2005). The role of students' attitudes and motivation in second language learning in online language courses. CALICO journal, 49-78.

Williams, E. (2011). Language policy, politics and development in Africa. Dreams and realities: Developing countries and the English language, 39-55. 